Article

\title{
Water and Energy Demand Management in Pressurized Irrigation Networks
}

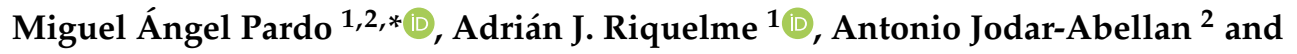 \\ Joaquín Melgarejo ${ }^{2}$ (D) \\ 1 Department of Civil Engineering, University of Alicante, 03690 San Vicente del Raspeig, Spain; \\ ariquelme@ua.es \\ 2 University Institute of Water and Environmental Sciences, University of Alicante, \\ 03690 San Vicente del Raspeig, Spain; antonio.jodar@ua.es (A.J.-A.); jmelgar@ua.es (J.M.) \\ * Correspondence: mpardo@ua.es; Tel.: +34-96-590-3400 (ext. 2472)
}

Received: 11 May 2020; Accepted: 25 June 2020; Published: 30 June 2020

\begin{abstract}
Minimizing energy expenditure is one of the main purposes of the managers of pressurized irrigation systems. From the energy consumption standpoint, they can reduce energy consumption by supplying a constant flow into the system (a scheme different from urban water pressurized networks in which water demands depend on users). Managers can keep energy demands (opening and closing valves) while meeting pressure restrictions. We developed a computer application in MATLAB containing a genetic algorithm to find the best moment to open and to close valves to minimize an objective function which measures the differences between the objective and the real injected flows. We tested this program in the pressurized irrigation network of the San Vicente Campus, University of Alicante (Southeast Spain) and we calculated the water and energy balance (from the later and present irrigation network) and the carbon credits not emitted to the atmosphere.
\end{abstract}

Keywords: water irrigation networks; MATLAB; energy audit; efficiency; carbon credits; rigid scheduled irrigation

\section{Introduction}

The International Energy Agency [1] declared that energy used in water processes ( $850 \mathrm{TWh}$ ) is $4 \%$ of global electricity consumption plus 50 million tons of oil equal of thermal energy (used for desalination technologies and diesel pumps). The situation is similar in Europe, where the water sector is the main purchaser [2] and the energy expenditure is proportionate to $3 \%$ of overall electricity consumption [3,4].

One challenge that utility managers must handle is to reduce energy consumption in urban water pressurized networks (WPN). Only adequate diagnosis entails efficient and sustainable operation. To date, the European Commission presents as one of its fundamental purposes to reduce emissions and establishes in its targets for 2050, such reduction with commercial, industrial and social transition strategies [5]. The European Union (EU) highlights the European dependency on oil and gas, which in 2018 produces $55 \%$ of the energy demand. The EU aims to reduce $20 \%$ of the full energy need for the year 2050 .

On a nationwide scale, we cannot relate the rise in energy expenditure to drip irrigation -linked to classical flood irrigation-But to the silent revolution [6] that assisted the demanding use of groundwater. In the 1970s, there was a progressive conversion of irrigation from gravity irrigation to pressurized irrigation. Between 1950 and 2007, the irrigated region grew 2.5 times, while water consumption doubled and energy expenditure multiplied by 19 [7]. Other authors quantified that energy consumption ranges between $0.28 \mathrm{kWh} / \mathrm{m}^{3}$ (dealing with water supply, conveyance and distribution) and $0.34 \mathrm{kWh} / \mathrm{m}^{3}$ (if water treatment is to be embodied) [8]. 
Researchers and professionals studied several strategies to reduce energy consumption [9], designing pressurized irrigation networks (PIN) layouts to minimize this requirement [10], improving PIN performance, network sectoring by grouping hydrants into sectors and organizing farmers irrigation time in rigid rotation scheduled irrigation [11,12], as enhancing the energy efficiency of pumping devices [13-15] or as advancing in water productivity $[16,17]$. Other approaches deal with variable speed drives [18-20], critical points control [21], with electricity costs [22,23] or with optimizing pressure regulation facilities location [24]. Other projects consider recovering part of the energy by installing pumps to perform as turbines (PATs) $[25,26]$ or by finding an efficient operating strategy for the optimal location and setting of pressure-reducing valves (PRVs) in water distribution systems. The latter practice is more widespread-but both approaches work by shortening the excess pressure in the fluid's energy to decrease water leaks and pipe stress. A fresh approach stated that PATs are a more cost-effective device and more sustainable than PRVs [27].

Solar energy emerges as a 'green' alternative because of the reduction in both non-renewable energy consumption and emissions to the environment [28]. To date, the European Commission, figures as one of its fundamental objectives the reduction of emissions and shows in its objectives for 2050, such reduction with economic, industrial and social transition strategies [5]. The European Union is working on the lines "Pathways for the transition to a net-zero greenhouse gas emissions economy and strategic priorities". The reductions in the production costs of photovoltaic (PV) arrays (30-60\% in 10 years; [29]) with the increasing oil prices have endeared this technology to decision-makers and practitioners. The rise in electricity prices in recent years since 0.0885 euros $/ \mathrm{kWh}$ in 2004 to 0.176 euros/kWh in 2017 [30] have contributed to enhancing this profitability.

The water-energy connection involves calculating energy audits of water distribution networks [31]. The key idea of grouping intakes into sectors to get a constant flow injected into the PIN showed it reduces energy consumption (15-30\%) [12,32]. With this premise, we study a PIN scheduled as rigid rotation delivery [33] (where the irrigation time given to each hydrant is not flexible) and we may open every hydrant, unit or subunit (and delivering water to crops) and identify that providing smaller pressure to consumers saves energy. We must supply a pressure greater than the minimum threshold pressure demanded by the service standards, but the closer to this (always above), the smaller the energy expenditure. Earlier research helped us calculate the lower network flow rate threshold (Qlow, th) [34], and show that according to network dimensioning, it is not possible to open every hydrant [35]. In short, two phenomena appear here, as greater flow rates involve higher energy dissipated in friction in pipelines and lower energy consumption in pumps (as they operate fewer hours). As PIN are oversized, the increase in the energy dissipated because of friction in pipes is lower than the energy savings in pumps [31]. Using a variable-frequency drive in pumping systems involves an energy consumption reduction, which will also be considered in our approach.

We arrange the energy "balance" question as an optimization problem with an objective function minimizing the discrepancies between measured and predicted flows injected into the PIN. We use the genetic algorithm (GA) [36] to schedule irrigation supplying a group of units to maximize water resources $[37,38]$ and to reduce energy consumption. We do the relevant PIN simulations using a hydraulic solver (in this approach, we run the EPAnet2 software [39]), and we compute energy consumption. To emphasize this procedure, we transform the irrigation schedule into an advance schedule with a regular flow, satisfying pressure specifications, providing the same volume and reducing operating hours of pumping devices. Thereafter, we turn energy savings into emissions reductions corresponding to each country energy mix and highlight the energy and emissions effect followed by energy demand management. This credit carbons saved can very much contribute to avoiding climate change (a credit of carbon represents one carbon dioxide $\mathrm{CO}_{2}$ ton). We use this method in a real pressurized irrigation network watering the garden of the University of Alicante (UA), located in San Vicente del Raspeig, Alicante, South East Spain. The calculation shows the potential energy savings which rise from managing energy consumption. 


\section{Materials and Methods}

\subsection{Hydraulic Input Data}

We request a calibrated irrigation model which considers water delivered to crops. Managers calibrate pressurized irrigation models by collecting observed flows in pipelines and pressures in consumption nodes. We can consider the model as calibrated if we achieve good agreement between the simulated (i.e., model predicted) and observed values over the entire simulation period. A calibrated model represents properly the measured data (reality). We likewise need the minimum pressure required by standards $\left(\frac{P}{\gamma}\right)_{\text {threshold }}(\mathrm{MWC})$, a value representing the smallest pressure for the correct operation of the sprinklers. We adopt this value regarding technical recommendations and the practical experience of gardeners. At lower values of pressure, the manufacturer does not sprinkler pop-up and proper functioning.

Once we have this information, we can perform hydraulic calculations. No errors should appear when running the hydraulic simulation as any error in the hydraulic solver returns an error in our simulation step (described in the following section. With the hydraulic model, we can get the irrigation time for every consumption node.

\subsection{Calculations in the Current Scenario}

\subsubsection{Upper and Lower Threshold Flow Rate}

The lower networks flow rate threshold $\left(Q_{\text {low,th }}\right)$ is the least injected flow which does not comply with the pressure conditions (for smaller flow rates, pressure specifications are satisfied). Meanwhile, the upper network flow rate threshold $\left(Q_{u p, t h}\right)$ is the greatest value maintaining the pressure above the standards (greater flow rates do not satisfy the pressure requirements), and they are infrastructure constraints [34]. This limit depends on the installation (not modifiable by managers) and the network layout, diameters, pipe materials, lengths and the flow delivered to plots (values depending on the irrigated surface and the number of emitters).

We can calculate the lower network flow rate threshold simulating various scenarios in a hydraulic simulation program such as EPAnet [39]. We can calculate the smallest pressure at each node in the simulation period running UAEnergy (a graphical user interface developed in Matlab [40]. Finding this lowest value involves a higher number of combinations and we made this calculation once as it is time-consuming, and their value is constant for the irrigation scheme.

\subsubsection{Water and Energy Audit of the Pressurized Irrigation Network}

We calculate the volume injected into the network $\left(V_{\text {inj }}(t)\right)$ and the volume infused/accumulated into the network by the tank $\left(V_{\text {tank }}(t)\right)$. This input volume into the PIN is balanced to the amount of the volume delivered to purchasers $\left(V_{R}(t)\right)$ and the volume wasted through leakages $\left(V_{L}(t)\right)($ Equation $(1))$.

$$
V_{\text {inj }}(t)+V_{\text {tank }}(t)=V_{R}(t)+V_{L}(t)
$$

We obtain these values in an extended period $\left(t_{p}\right)$, which can take values such as 1 year, 1 month, 1 day, etc.). We divide this duration time into $m_{\mathrm{i}}$ intervals of time $\left(\Delta t_{k}\right)$ (being this $\Delta t_{k}$ the length of the pattern time step; 5, 10, 15, $30 \mathrm{~min}$, etc.). Thus, we get the total volume injected in the extended period $\left(t_{p}=m_{i} \cdot \Delta t_{k}\right)$ from the sum of the water injected in each of the $m_{\mathrm{i}}$ the time interval of the steady-state simulation.

UAenergy again computes the energy audit in water distribution networks (in fact, this is its key objective). We calculate the energy supplied by reservoirs $\left(E_{N}\left(t_{p}\right)\right)$, by pumps $\left(E_{P}\left(t_{p}\right)\right)$ and by tanks $\left(\Delta E_{C}\left(t_{p}\right)\right)$. This input energy into the PIN is equal to the energy delivered to the users $\left(E_{U}\left(t_{p}\right)\right)$, the energy lost through water losses $\left(E_{L}\left(t_{p}\right)\right)$ and the energy dissipated in friction at pipes $\left(E_{F}\left(t_{p}\right)\right)$. This balance results in Equation (2). 


$$
E_{n}\left(t_{p}\right)+E_{p}\left(t_{p}\right) \pm \Delta E_{c}\left(t_{p}\right)=E_{u}\left(t_{p}\right)+E_{l}\left(t_{p}\right)+E_{f}\left(t_{p}\right)
$$

The flow injected into the network is the parameter to be optimized here. It is widely known that constant flows injected into the PIN (always meeting pressure restrictions) involve minimum energy consumption. In this stage, we calculate the $V_{i n j}(t)$ (through the total simulation time $t_{p}=m_{i} \cdot \Delta t_{k}$ ) and we aim to supply the same volume with a constant flow (the lower threshold flow rate, Figure 1). With this new data, the new simulation time should be Equation (3).

$$
k_{i}=\operatorname{ceil}\left(\frac{V_{i n j}(t)}{Q_{\text {low }, t h} \times \Delta t_{k}}\right)
$$

Being $k_{\mathrm{i}}$ the intervals of time required to supply the $V_{i n j}(t)$ with a constant flow.

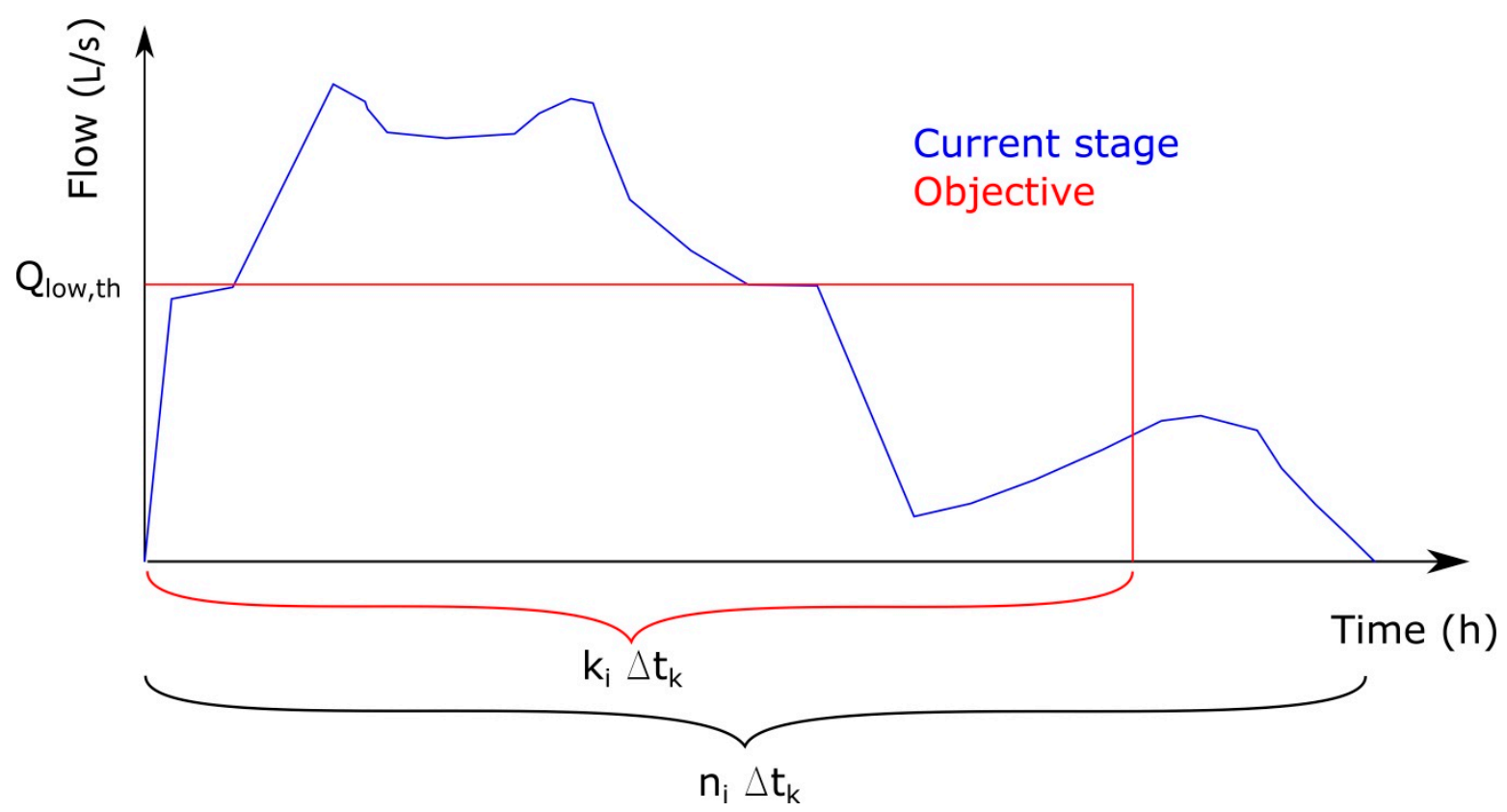

Figure 1. Injected and objective flow in an irrigation network.

\subsubsection{Carbon Credits Calculation}

We consider $\mathrm{CO}_{2}$ emissions from every energy source. The standard values of $\mathrm{CO}_{2}$ per $\mathrm{kWh}$ emitted by every energy source such as natural gas, $554 \mathrm{~g} / \mathrm{kWh}$; oil burned, $865 \mathrm{~g} / \mathrm{kWh}$, coal burned, 1432 and others (nuclear and renewable sources) $0 \mathrm{~g} / \mathrm{kWh}$ [41].

\subsection{Objective Function}

The objective function is to obtain as good as the possible agreement between the simulated (i.e., model predicted) and observed values over the entire simulation period. Here, this goal is achieved by minimizing the root-mean-square error (RMSE) between observed and simulated flows (Equation (4)):

$$
\mathrm{RMSE}=\sqrt{\frac{\sum_{j=1}^{n_{m Q}}\left[Q_{l, t_{j}}^{o b s}-Q_{l, t_{j}}^{s i m}\right]^{2}}{n_{m Q}}}
$$

where $n_{m Q}$ are the number of flow observations at pipe/link L, $Q_{p, t_{j}}^{o b s}$ and $Q_{p, t_{j}}^{s i m}$ are the observed and simulated flow at link $L$ and referred at the time $t_{j}$. Here, the time of observation $t_{j}$ always coincides with the simulated time, but in other cases $Q_{p, t_{j}}^{s i m}$ may be interpolated from the computed data at link 
$L$ (just before and after time $t_{j}$ ). Note that if the observed flow coincides with the pattern time step, $n_{m Q}=k_{i}$.

\subsection{Optimization Parameters}

We gather the optimization parameter considered here in a $1 \times n$ (being $n$ the number of consumption nodes in the irrigation network) vector has $n$ integer numbers $\left(X_{1}, X_{2}, \ldots, X_{n}\right)$. These numbers reveal the starting irrigation time of each consumption node. Note that any additional restriction involves reducing this potential $\left(X_{1}, X_{2}, \ldots, X_{n}\right)$ values.

As data to our problem, we may retrieve from the PIN model the irrigation duration for each consumption node. This is a $1 \times n$ integer vector $n$ integer numbers $\left(D_{1}, D_{2}, \ldots, D_{n}\right)$ showing the number of $\Delta t_{k}$ intervals of time per node.

EPAnet2 is a demand-driven water distribution network modeling software that uses temporal demand pattern multipliers to represent a diurnal demand curve, i.e., the temporal variation of demand, often for $24 \mathrm{~h}$. In the case study shown here, there is no a priori knowledge of the demand pattern multipliers (DPM) values. We only know these values must be integers from 1 to $k_{i}-d_{i}$. This means that if consumption node irrigates for $d_{1} \cdot \Delta \mathrm{t}_{\mathrm{k}}$ minutes, the irrigation start time $\left(\mathrm{X}_{1}\right)$ may be any of values oscillating from 1 to $k_{1}-d_{1}$ (if the number is 1 , we irrigate from 0 to $d_{1} \cdot \Delta t_{k}$, and if the number is $k_{1}-d_{1}$, we irrigate from $\left(k_{1}-d_{1}\right) \cdot \Delta t_{k}$ to $k_{1} \cdot \Delta t_{k}$.

With these numbers, each combination creates a binary matrix $(\mathrm{n} \times \mathrm{m})$ described with Equation (5).

$$
R_{i j}=\left\{\begin{array}{c}
0, \text { if } j<X_{i} \\
1, \text { if } X_{i} \leq j \leq\left(X_{i}+D_{i}\right) \\
0, \text { if } j>\left(X_{i}+D_{i}\right)
\end{array}\right.
$$

where each row shows the irrigation time of each node (from 1 to $n$ ) and the column $\mathrm{j}$ shows the instant of time where the i-node is delivering water. As an example, if the length of the pattern time step is $10 \mathrm{~min}$, if we select the values $X_{2}=1$ and $d_{2}=2$, we know that node 2 is supplying water to the garden from $0: 10 \mathrm{~h}$ and it will last for $2 \Delta t_{k}=20 \mathrm{~min}$. Other values as $\mathrm{X}_{10}=6$ and $\mathrm{d}_{10}=4$ shows that node 10 irrigates from 1:00 to 1:40 h $\left(4 \Delta t_{k}=40 \mathrm{~min}\right)$.

\subsection{Optimization Algorithm}

In our approach, we adopt the integer version of the GA algorithm since we can assign all the genes with integer numbers. Now, we embody these earlier results, but our ambition is to diminish energy consumption. Hence, we do the relevant PIN simulations using the EPAnet2 software [39], and we compute energy expenditure [31]. We get this from the energy equation in integral form, and its time integration extended over a period (day, month or year). To ease this step, we have used the software UAenergy [40], planned for academic and professional purposes, to calculate the energy audit losses in PINs. The program package and source codes are available at https://bit.ly/2FbNqdr. The analysis allows checking for the energy, showing that the energy balance is maintained.

We can solve constrained and unconstrained optimization problems with a GA [36]. Being the GA a method based on the natural selection which changes a population of individual solutions including selection + crossover + mutation + elitism [42-45]. At each step, the algorithm selects individuals from the current population and uses them as parents to produce the children for the next generation. Over consecutive generations, the population drives toward an optimal resolution. We use this GA as an alternative to other optimization algorithms, where the objective function is not continuous or nonlinear, non-differentiable or stochastic. The GA algorithm makes a population of points at each iteration. The best point in the population approaches an optimal solution, and the algorithm takes the children for the next population by computation, which uses random number generators.

The accompanying draft outlines how the GA works:

1. The algorithm creates a random initial population; 
2. It creates a sequence of new populations. At each step, the algorithm uses the individuals in the current generation to create the next population (children) according to the following steps:

- Scores each member of the current population by computing its fitness value (the raw fitness scores);

- Scales the raw fitness scores to convert them into a more usable range of values (expectation values);

- It selects members called parents based on their expectation;

- The GA chooses individuals in the current population with lower fitness as elite. They pass these elite individuals to the next population;

- Produces children from their parents. The GA produce children by changing a single parent-mutation - or by combining the vector entries of a pair of parents, crossover;

- Replaces the current population with the children to form the next generation.

3. The algorithm stops when it meets the stopping criteria (reaching the maximum number of iterations or where the calculated objective function is below a $\varepsilon$ value equal to $10^{-15}$ ).

We create options of the GA algorithm using the global optimization toolbox in MATLAB ${ }^{\circledR}$ and created the random first population with a 64-bit multiplicative lagged Fibonacci generator [46]. The lower bound and upper bound values range between $1 \leq X_{i} \leq\left(k_{i}-d_{i}\right)$ for the $n$ values of $X_{i}$. Note that the potential values of each consumption node depend on the duration $1 \times n$ integer vector described in Section 2.4. The positive integer specifying how many individuals in the current generation survive to the next generation is equal to 15 (Elite count), the fraction of the population at the next generation, not including elite children, that the crossover function creates is equal to 0.8 (recommended value by the software). Migration options specify how individuals move between subpopulations, we set migration direction to Both ('both'), as the $n$th subpopulation migrates into both the $(n-1)$ th and the $(n+1)$ th subpopulation. The migration factor specifies how many individuals move between subpopulations, and we set this number to 0.2 , this means that for example, if individuals migrate from a subpopulation of 50 individuals into a subpopulation of 100 individuals, the number of individuals that migrate is $0.2 \times 50=10$. The maximum iterations before the algorithm halts are $2 \times 10^{5}$. The result of the optimization problem is a $1 \times n$ integer vector which minimizes the objective function (Equation (4)).

\subsection{The Process to Balance the Irrigation Network}

The general flowchart of this method visualizes the process (Figure 2). We describe it here:

Step 1: It shows the input hydraulic data required (illustrated in Section 2.1).

Step 2: We should incorporate the values of the upper and lower threshold flow rates for the irrigation pressurized network if know these figures or to calculate them from the model (Section 2.2.1). We do the water and energy audit calculations (Section 2.2.2). Later, we calculate the carbon $\mathrm{CO}_{2}$ emissions (Section 2.2.3).

Step 3: With the water consumption and the lower threshold flow rate, we calculate the new total irrigation time at a constant flow rate (Equation (3)). Then, the GA algorithm (Section 2.5) minimizes the objective function (defined in Section 2.3), changing the starting irrigation time of every consumption node (Section 2.4).

Step 4: The result of the GA algorithm returns the best value of the optimization parameters. Then, we reduce the number of hours that the pumps are working; we calculate the water and energy audit, and we calculate the emissions. We can now calculate the savings reached by our method. 


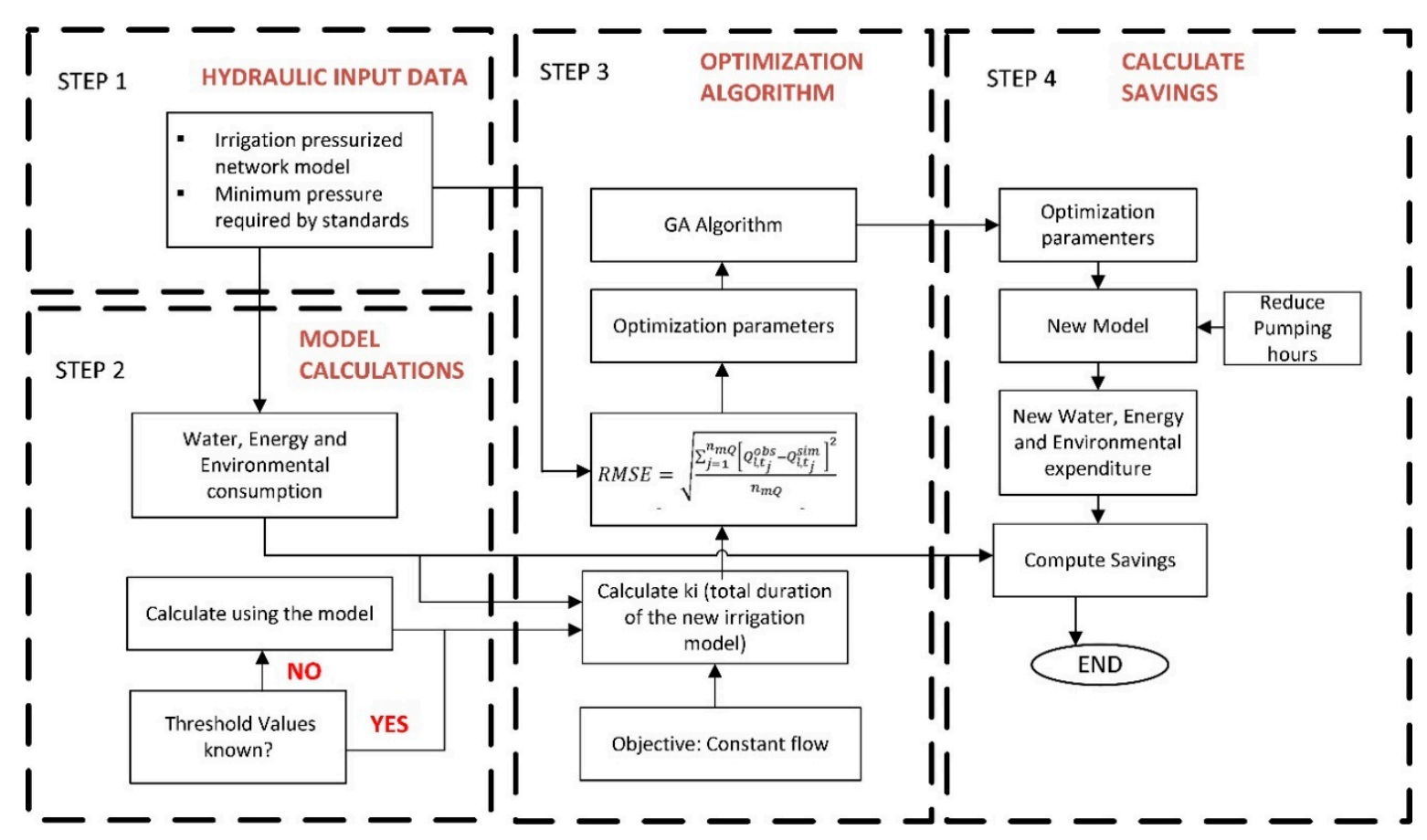

Figure 2. Workflow for the process to balance the irrigation network.

\section{Case Study}

To explain this procedure, we analyze the programmed sprinkling device used for watering the garden of the University of Alicante, SE Spain ( $38^{\circ} 23^{\prime} 4.06^{\prime \prime}$ N, $0^{\circ} 30^{\prime} 44.06^{\prime \prime}$ W; Figure 1), (Figure 3; Case 0 ). The irrigation zone of this garden has grown through time, and the gardeners have included new species to the grass meadow (i.e., Festuca arundinacea and Poa annua). We divided the plot into hydro-zones grouped corresponding to the landscape coefficient method depending on water needs and crop evapotranspiration values. For the months of greatest water need, overall water needs are 1.7 and $3.9 \mathrm{~L} \cdot \mathrm{mm}^{-2} \cdot \mathrm{day}^{-1}$, comparable to the water use of the least and most exposed areas of the garden.

We supply the water into the irrigation pressurized network by the reservoir (lake near the University) although the irrigation network allows taking it from the drinking WPN in San Vicente del Raspeig.

The full scheme comprises a reservoir, a pumping house, (a water treatment plant is downstream of the lake) and the water irrigation piping network (Figure 3). We spread the latter over an area of $0.67 \mathrm{Km}^{2}$ and consist of two parts: one dating back to the first part of the University and the second one built later. The network is mixed mesh and the pipe materials are fiber cement and PVC. The network contains $23 \mathrm{~km}$ of pipes (891 pipes whose diameter varies among 1"-8") (Hazen-Williams roughness coefficients equal to 100) supplying water to some 160 consumption nodes We provide each consumption node with an electro valve that controls when to irrigate (valve opened) each plot or when not to irrigate (valve closed). The maximum and minimum base demands consumption is $0.83 \mathrm{~L} / \mathrm{s}$ and $25.97 \mathrm{~L} / \mathrm{s}$. Opening and closing times are the optimization criterion in our approach. The irrigation network is notably flat, the difference in height between the highest and lowest elevation is $93-90=3 \mathrm{~m}$.

The irrigation network is equipped with a pumping station consisting of 4 pumps working in parallel. The specific model of the pump is "EVM 32 2-0F5/4.0" of the "Ebara" company [47], a vertical multistage electric pump in cast iron, The pump curve is $H=-0.2163 Q^{2}+0.3509 Q+44.713$. The pump efficiency is $\eta=0.75$ for simplicity, the power is equal to $4 \mathrm{~kW}$ and the nominal flowrate is equal to $540 \mathrm{~L} / \mathrm{min}$, being their corresponding head equal to $26.5 \mathrm{~m}$. 


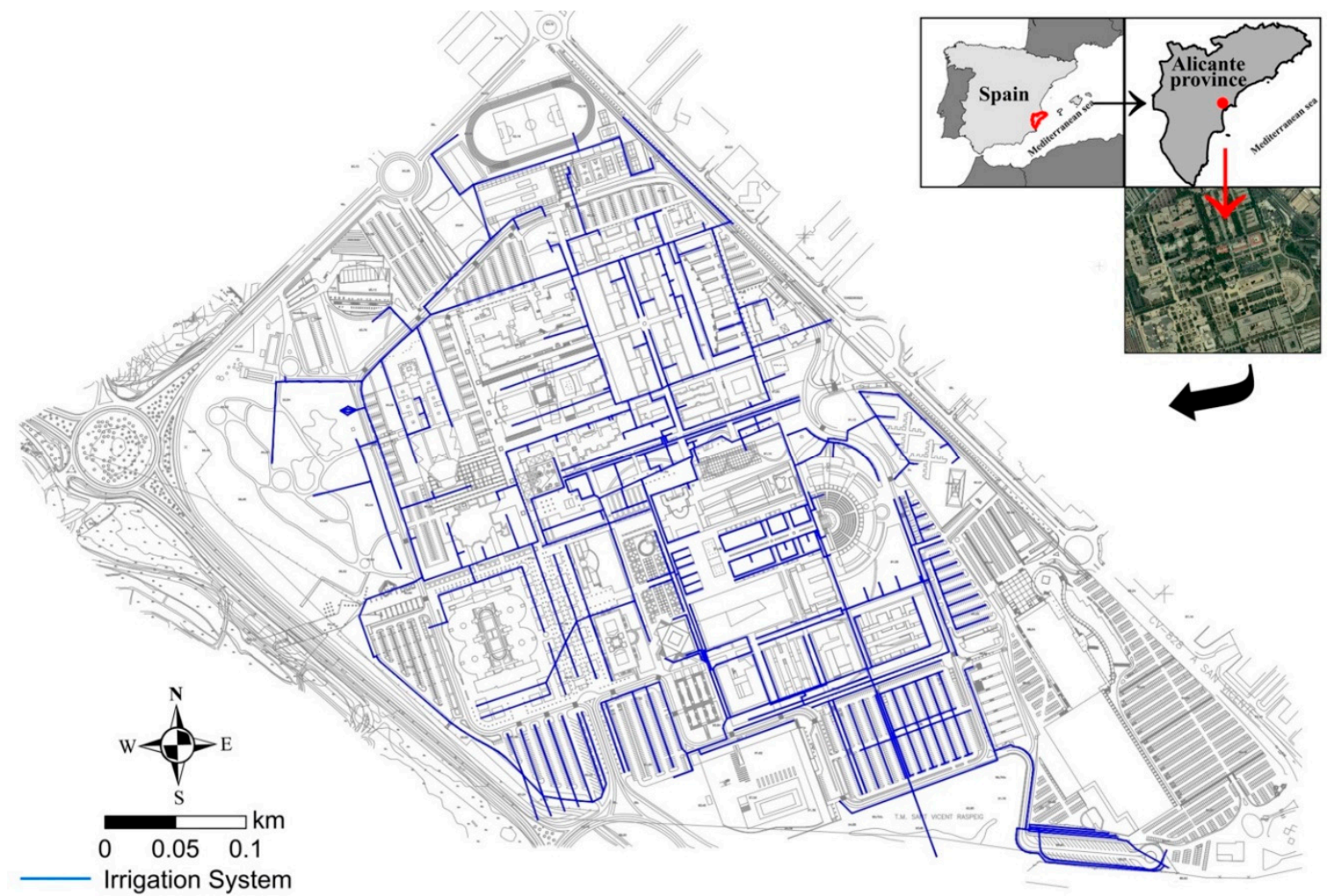

Figure 3. Location of the study area: University of Alicante-Irrigation system.

The duration of the extended period simulation is $72 \mathrm{~h}$ (as this period represents the irrigation time). The gardeners repeat this pattern twice per week (Figure 4). The pattern time step represents the time interval after which, a change in time patterns is produced we set pattern time step to $15 \mathrm{~min}$ in this case study, a value which allows flexibility through the management and operation of the irrigation network. To get real values of the demand pattern multipliers coefficients; we set the hydraulic time step to $5 \mathrm{~min}$. The 72-h demand multiplier patterns are used to represent the relative temporal demand variations, being 1 for opened valves and 0 if locked.

The technicians and gardeners selected the irrigation management plan on rotation scheduled delivery [33]. They grouped electro valves in irrigation segments operating remote-controlled.

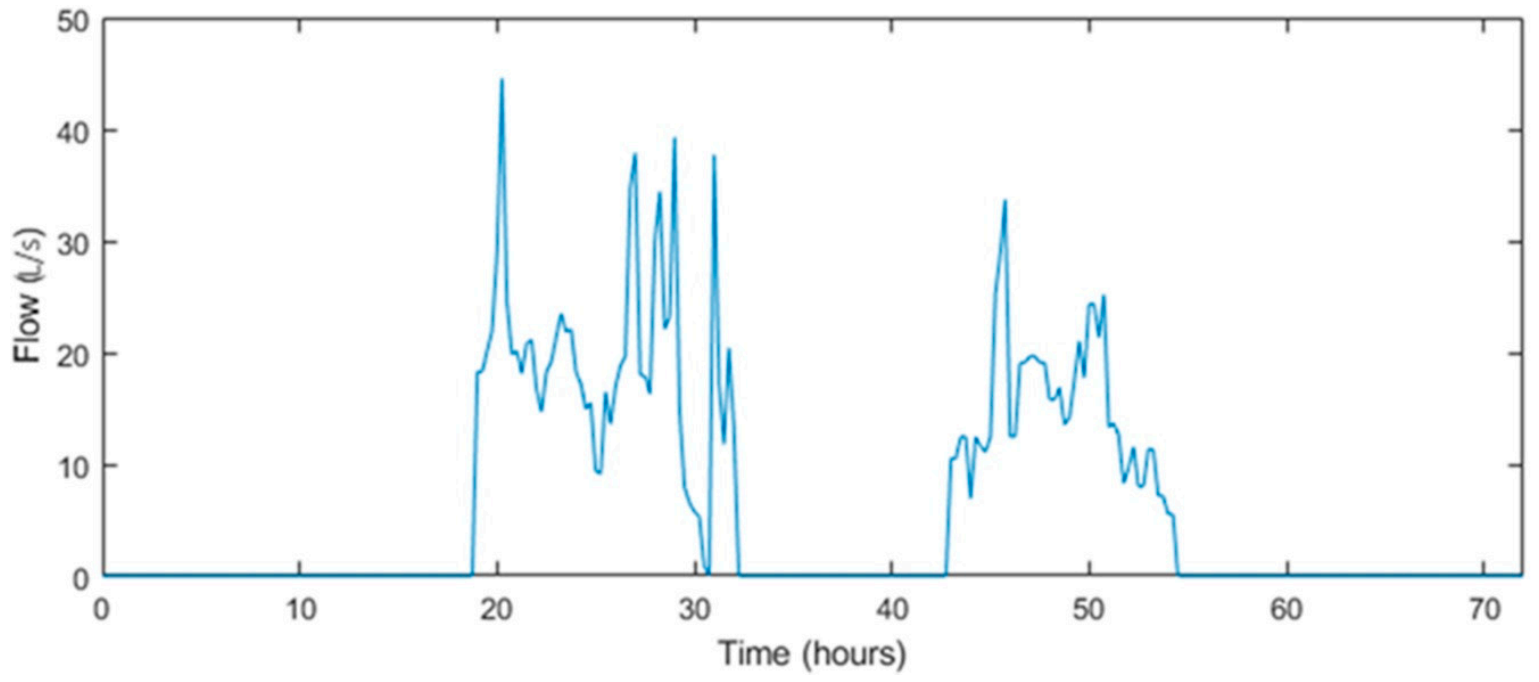

Figure 4. Injected flow into the irrigation network. 


\section{Results and Discussion}

\subsection{Injected Flow into the System for the UA Irrigation Network}

The analysis shows that the flow injected is divided into 2 blocks (Figure 5), the first concerns the volume of water delivered from 19:00 h on the first day (Sunday or Wednesday) to 8:00 h on the second day (Monday or Thursday) with an interval at 6:45 a.m. just $15 \mathrm{~min}$. The second concerns the volume of water delivered from 19:00 h on (Monday or Thursday) and ends at 6:30 h on (Tuesday or Friday).

\subsection{Lower Network Flowrate Threshold}

To test the relationship between the smallest pressure and inlet flow, we worked out 15,000 simulations (Figure 5). In each of the simulations, we open several hydrants and subunits. The inlet flow rates then followed differs from 0 to $50 \mathrm{~L} / \mathrm{s}$ (the number of expenditure nodes opened reaching from one to 160). The lower network flow rate threshold is $28.57 \mathrm{~L} / \mathrm{s}$ (the smallest flow rate that may encompass at least pressure below $25 \mathrm{MWC}$, marked in black in Figure 6) and the upper network flow rate threshold is $51.37 \mathrm{~L} / \mathrm{s}$ (the greatest flow rate for which we can maintain pressure specifications). We have performed the 15,000 simulations using random consumption values for the irrigation pressurized network. We consider the potential risk of combining several valves opening involving pressures below the required by standards $\left(\frac{P}{\gamma}\right)_{\text {threshold }}=25 \mathrm{~m}$. w; (c) The graph in brown is the latest 5000 simulations performed among the specific values among the upper and lower threshold flow rates.

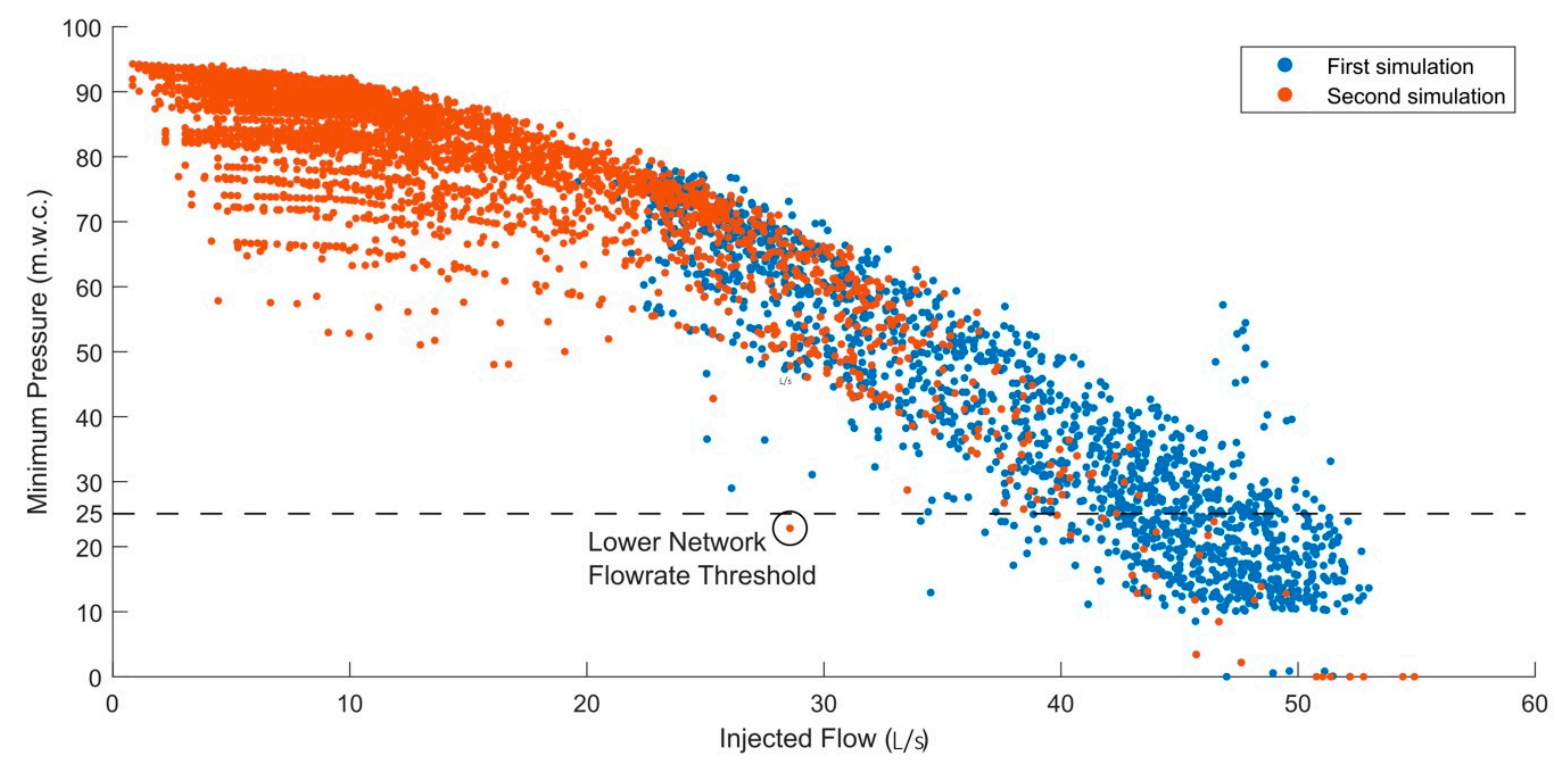

Figure 5. Simulations performed to calculate upper and lower threshold values (infrastructure constraint). The black mark shows the lower network flowrate threshold.

The lower network flow rate threshold is a value in which utility managers know that the irrigation pressure network will work meeting the pressure standards (as observed after performing the previous simulations, Figure 5). We get the best energy efficiency combination in the upper network flow rate as we supply higher flow rates. Should we have chosen an alternative with the more injected flow? If we had, these combinations (injected flow rates equal to $51.37 \mathrm{~L} / \mathrm{s}$ ) we get no certainty that we meet the service standards. As the lowest threshold gains a very important role, we calculate the probability of meeting pressure requirements for the injected flow rate. We group the injected flow rates in a $2 \mathrm{~L} / \mathrm{s}$ range, we will get the successful simulations performed per every group (Table 1).

In the flow rates among $25.56 \mathrm{~L} / \mathrm{s}$ and $51.37 \mathrm{~L} / \mathrm{s}$, we found 1550 simulations, 1100 of them successful. We may get the probability of meeting pressure conditions if we combine flow with the 450 unsuccessful simulations. If the flow rate is above $28.57 \mathrm{~L} / \mathrm{s}$, the probability of not matching the 
pressure standards is $1 / 450$ (or $1-1 / 450=99.77 \%$ of matching), and later the flow rate is above $3408 \mathrm{~L} / \mathrm{s}$ (the second combination under pressure standard) the probability of not meeting the standards is $2 / 450$ (or $1-2 / 450=99.55 \%$ of meeting them). Extrapolating this, we identify the relationship between probability and flow rate (Figure 6).

Table 1. Results grouped by flow rates.

\begin{tabular}{cccc}
\hline Flowrate (L/s) & Simulations & Successful Simulations & Percentage (\%) \\
\hline$<34$ & 1112 & 1111 & $99.91 \%$ \\
$34-36$ & 117 & 115 & $98.29 \%$ \\
$36-38$ & 89 & 85 & $95.51 \%$ \\
$38-40$ & 121 & 113 & $93.39 \%$ \\
$40-42$ & 99 & 79 & $79.80 \%$ \\
$42-44$ & 159 & 105 & $66.04 \%$ \\
$44-46$ & 175 & 80 & $45.71 \%$ \\
$46-48$ & 162 & 54 & $33.33 \%$ \\
$48-50$ & 144 & 36 & $25.00 \%$ \\
$50-52$ & 88 & 5 & $5.68 \%$ \\
\hline
\end{tabular}

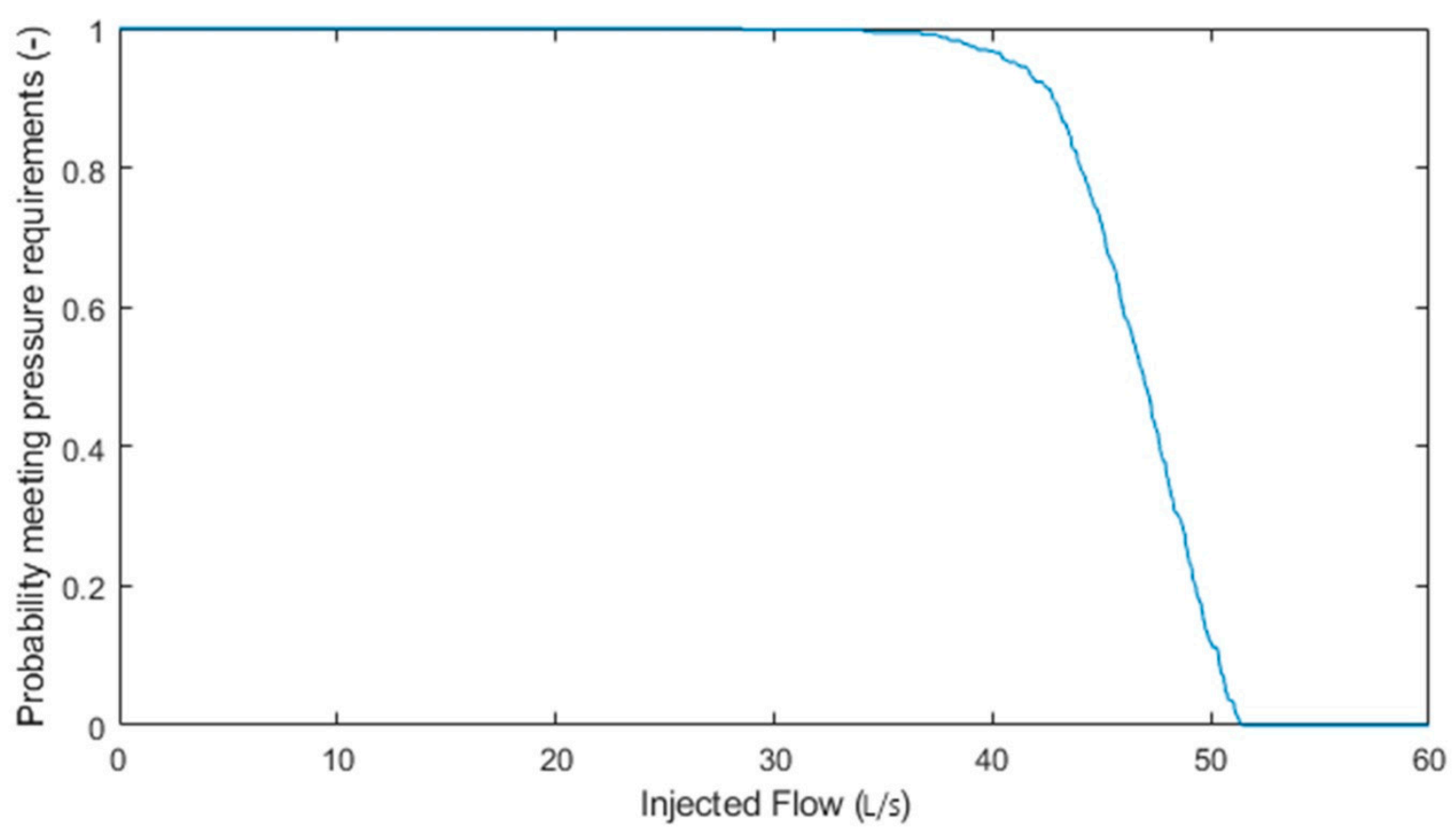

Figure 6. Probability of meeting pressure requirements for several values of injected flow.

In this new scheme, three pumps are running in parallel providing $9.52 \mathrm{~L} / \mathrm{s}$ with each one (values very close to its best efficiency point, $9 \mathrm{~L} / \mathrm{s}$ ). We have installed a variable-frequency drive to control the head added to the flow and optimized its speed (once the flow rates are constant) for a value equal to $\alpha=0.7$ (a value which allows the pump to satisfy the requested flow rate) reducing the excess of pressure.

\subsection{New Model of the Irrigation Pressurized Network}

There are 160 consumption nodes in the UA irrigation network, $n=160$. Being the maximum water demand equal to $861.94 \mathrm{~L} / \mathrm{s}$ (all hydrants opened). The irrigation duration of the nodes varies from $15 \mathrm{~min}$ to $8 \times 15=2 \mathrm{~h}$.

We can calculate the intervals of time $\left(k_{i}\right)$ required to supply injected volume $V_{\text {inj }}(t)=1539.85 \mathrm{~m}^{3}$, as a constant flow $Q_{\text {low }, t h}=28.57 \mathrm{~L} / \mathrm{s}$ (Section 4.3 ) (a value that complies with the pressure conditions) with Equation (6). 


$$
k_{i}=\operatorname{ceil}\left(\frac{V_{i n j}(t)}{Q_{l o w, t h} \times \Delta t_{k}}\right)=\operatorname{ceil}\left(\frac{1539.85 \times 10^{3}}{28.57 \times 900}\right)=\operatorname{ceil}(59.88)=60
$$

Being the new simulation time equal to $t_{p}^{*}=k_{i} \cdot \Delta t_{k}=900 \mathrm{~min}=15 \mathrm{~h}$. With this information, we know that the values of the result provided are integers from 1 to $k_{i}-d_{i}$. For example, the two first consumption nodes are $\mathrm{n} 8$ and $\mathrm{n} 9$ and their irrigation duration is equal to 2 and $4 \Delta t_{k}$ minutes $\left(d_{1} \cdot \Delta t_{k}\right.$ $=30$ and $60 \mathrm{~min}$ ). The irrigation starts time $X_{1}$ and $X_{2}$ may be any integer oscillating from 1 to $k_{i}-d_{i}$. In other words, $X_{1}$ and $X_{2}$ may be any integer ranging from 1 to $60-2=58$ or from 1 to 56 .

The solution of the optimization problem returns the least RSME value equal to 1.8643. Discrepancies among the objective and calculated values are depicted in Figure 7.

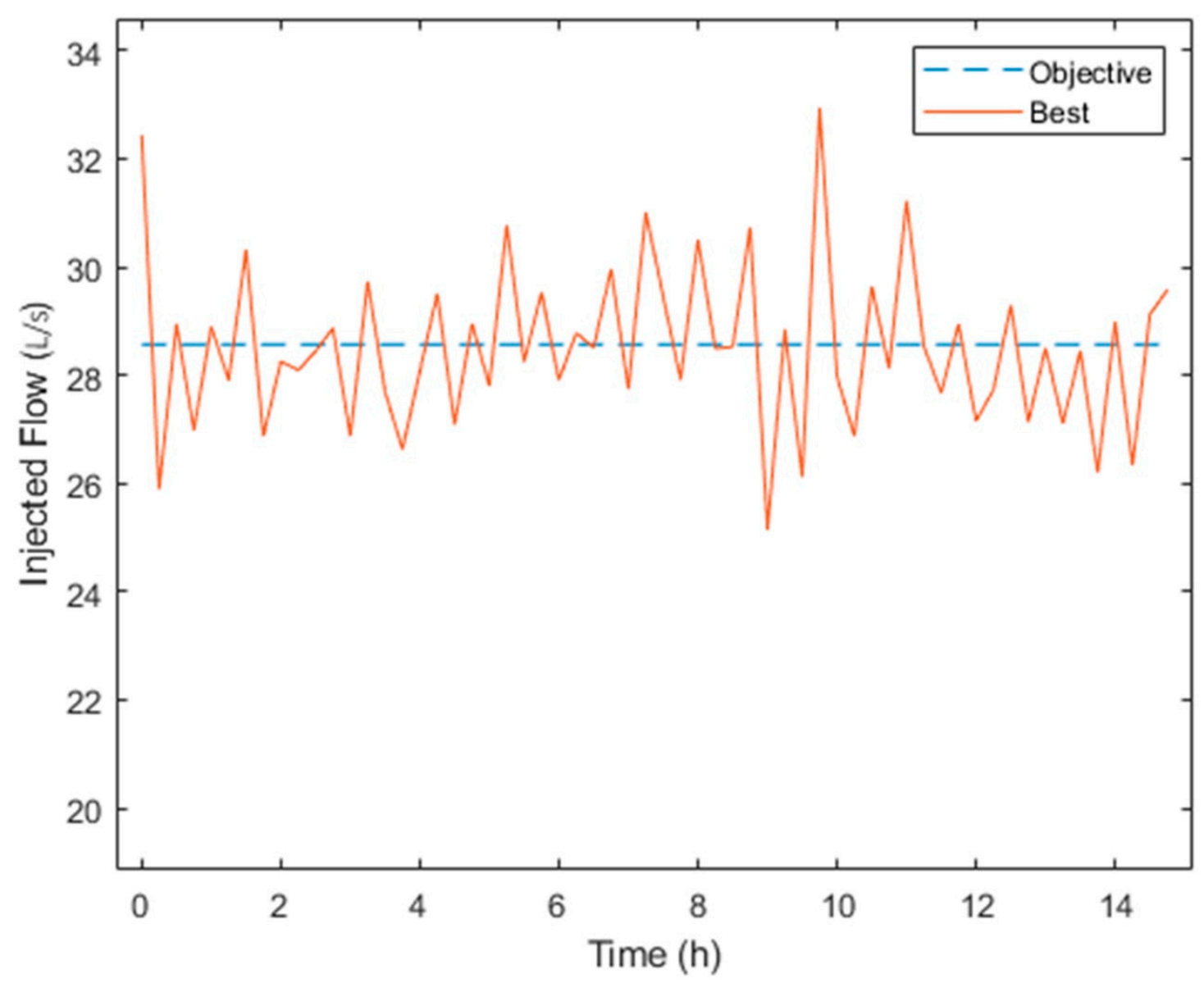

Figure 7. Injected objective flow and best solution found by genetic algorithm (GA) algorithm.

\subsection{Energy Audit of the UA Irrigation Network Case 0 and Case I}

UAEnergy [40] is a software that calculates the energy audit of a pressurized water network (Section 2.2.3). We get this from the energy equation in integral form, and its time integration extended over a period (day, month or year). We calculate this energy audit for the current case and the new model generated by the GA algorithm (Table 2).

Being $E_{\mathrm{N}}$ the energy supplied by reservoirs and $E_{\mathrm{P}}$ the energy supplied by pumps. These two terms represent the input energy into the PIN, a value that is equal to the sum of energy delivered to the users $\left(E_{\mathrm{U}}\right)$ and the energy dissipated in friction at pipes $\left(E_{\mathrm{F}}\right)$. The greatest part of the energy spent in our case study comes from the reservoir (lake) as we are studying the water pressurized network management which gathers water from the lake. We are not debating the energy footprint of water (got by a desalination plant in the University of Alicante). 
Table 2. Results from the energy audit.

\begin{tabular}{ccc}
\hline Energy Audit & Case 0 & Case I \\
\hline Injected water $\left(\mathrm{m}^{3}\right)$ & 1539.53 & 1539.1 \\
Delivered water $\left(\mathrm{m}^{3}\right)$ & 1538.87 & 1538.87 \\
Real losses $\left(\mathrm{m}^{3}\right)$ & 0 & 0 \\
Total duration $(\mathrm{h})$ & 72 & 15 \\
En $(\mathrm{kWh})$ & 590.48 & 590.30 \\
$E \mathrm{p}(\mathrm{kWh})$ & 143.66 & 46.32 \\
$E \mathrm{u}(\mathrm{kWh})$ & 701.94 & 601.49 \\
$E \mathrm{f}(\mathrm{kWh})$ & 31.88 & 35.05 \\
\hline
\end{tabular}

\subsection{Environmental Calculations}

We calculated $\mathrm{CO}_{2}$ emissions (tons) in the pump's operation (Table 3). According to each country energy mix, we can calculate the emissions savings. The energy mix in Spain is oil-fired, $31.8 \%$, natural gas, $13.5 \%$; coal-fired $21.0 \%$; nuclear and renewables $33.7 \%$ for the year 2017 [ 48 ]. The energy consumed is 191.54 and $61.77 \mathrm{kWh}$ for case 0 and I (the pump efficiency equal to 0.75 is considered here). The $\mathrm{CO}_{2}$ emissions are computed in Table 2. In the calculations performed, note that we irrigate in these $72 \mathrm{~h}$, which is the half of the water required weekly.

Table 3. $\mathrm{CO}_{2}$ emissions for Case 0 and Case I.

\begin{tabular}{ccccccc}
\hline $\begin{array}{c}\mathrm{CO}_{2} \\
\text { Emissions }\end{array}$ & Mix (\%) & Case 0 & Case I & $\begin{array}{c}\text { Production } \\
(\mathbf{g} / \mathbf{k W h})\end{array}$ & $\begin{array}{c}\text { Case 0 Emissions } \\
\text { (Tons/year) }\end{array}$ & $\begin{array}{c}\text { Case I Emissions } \\
\text { (Tons/year) }\end{array}$ \\
\hline Oil fired & 31.8 & 60.91 & 19.64 & 865 & 5.49 & 1.77 \\
Natural gas & 13.5 & 25.86 & 8.34 & 554 & 1.49 & 0.48 \\
Coal fired & 21 & 40.22 & 12.97 & 1432 & 6.01 & 1.94 \\
\hline \multicolumn{7}{c}{$\mathrm{CO}_{2}$ emissions } \\
\hline
\end{tabular}

\subsection{Discussion}

The average water consumption is $3077.74 \mathrm{~m}^{3} \cdot \mathrm{week}^{-1}$ for both cases. The results bear no surprise if we get a constant flow injected into the irrigation network; we reduce energy consumption and the number of hours the pumps are running. Table 2 shows we somewhat increase friction (35.05$31.88=3.17 \mathrm{kWh})$, but we also get energy consumed by pumps savings $(143.66-46.32=101.34 \mathrm{kWh})$. We reduce the surplus of pressure at irrigation plots as we deliver water close to the minimum threshold pressure, but always above this limit. This energy savings means 10,336.68 kWh/year. And 8.80 tons of $\mathrm{CO}_{2} /$ year not emitted to the atmosphere.

The pumping hours in Case 0 are 24, 22.5, 11.5 and 7, while Case I, three pumps work for $15 \mathrm{~h}$ and $15 \mathrm{~min}$ each, being one pump turned off for the entire day (reserved for managerial purposes). In case I we save $29 \mathrm{~h}$ and $15 \mathrm{~min}$ which means $2983.5 \mathrm{~h}$ per year. In case 0 , we need $0.093 \mathrm{kWh} / \mathrm{m}^{3}$ (a common value for surface water in urban WPN; $0.058 \mathrm{kWh} / \mathrm{m}^{3}$ [49]) and this value decreases up to $0.028 \mathrm{kWh} / \mathrm{m}^{3}$ in Case I, saving $0.065 \mathrm{kWh} / \mathrm{m}^{3}$. We can consider this irrigation network as flat (as before mentioned) and the $80.4 \%$ of the energy comes natural energy (or only $19.6 \%$ comes from pumping devices). These energy savings must be more relevant in hilly irrigation networks directly supplied by pumps.

In this approach, we were particularly conservative for selecting the aim injected flow $(28.57 / \mathrm{s}$ with a $99.91 \%$ percentage of success (Table 1). Higher energy saving could have been taken with greater risk (i.e., if the injected flow were $38 \mathrm{~L} / \mathrm{s}$, the risk of not meeting pressure requirements were $100-95.51=4.49 \%)$.

One limitation of our research is that irrigation time in our PIN should be proportional to the pattern time step in the model. For example, if the pattern time step is $15 \mathrm{~min}$, we can irrigate a plot for 15, 30, $45 \mathrm{~min}$, etc. Authors appreciate that if the pattern time step is one minute, we may get any irrigation time, but the procedure complicates. We make the irrigation data vector as an integer $1 \times n$ vector (being $n$ the number of consumption nodes in the irrigation net). This is the time that every consumption junction is 
open (and feeding the plots). In our problem, once the electro valve or hydrant is open, we supply the demanded water in this plot; we do not irrigate this demand in two periods of time.

Another condition is that to deal with water and energy demand, the schedule must be rigid rotation delivery (where the irrigation time each hydrant is not flexible) [50].

\subsection{Future Developments}

We submitted a proposal to the Ministry of Spain in his last call, "Knowledge generation and scientific and technological strengthening of the R\&D\&i system". This project comprises assembling a pilot plant of a standalone PV pressurized irrigation network, where we can handle the energy demand. We wait to build a graphical user interface (GUI) to decide the objective energy demand, providing them to pick if they want stable injected flow (as represented in this text) or a parabolic energy demand (same than the energy generated in PV arrays). The second will minimize the number of PV panels needed.

\section{Conclusions}

Utility managers, technicians and gardeners can change water and energy demand in pressurized irrigation networks (different from urban WPN, where water demands depend on final users). They can deliver water to crops at every hour of the day. With this premise, we adjust the irrigation time for every consumption node getting relevant energy savings (lower energy consumption in pumping devices).

We must calculate the constant flow rate meeting standard need (lower threshold flowrate which keeps pressure above the threshold; $25 \mathrm{MWC}$ ) and the total duration of the recent simulation period (Figure 1). Both values must achieve the same volume delivered to crops as in the current state to allow comparison. To reach this objective, we proposed an objective function (the RMSE) which assesses the variations between the target flowrate and the real injected flow. We optimize an integer constrained vector considering this as an optimization problem with a GA included in a programming software as MATLAB $^{\circledR}$. The GA detects the moment where we must open and/or close valves to minimize energy use.

This approach was tested in the pressurized irrigation network in San Vicente Campus, University of Alicante (southeast Spain). It resulted in $10.4 \mathrm{MWh}$, nine tons of $\mathrm{CO}_{2}$ and 3000 pumping hours saved per year in a flat PIN (not the most favorable scenario). We can save $0.065 \mathrm{kWh} / \mathrm{m}^{3}$ without no economic investments. This procedure must be the first step of a protocol to assess energy requirements. This method can help local water management authorities in the decision-making process and tasks related to water and energy demand.

Author Contributions: M.Á.P. and A.J.R. performed modeling and analysis, designed research task and performed discussion. A.J.-A. and J.M. cooperated on the research task, wrote partially the manuscript, provided literature and adapted figures. All authors have read and agreed to the published version of the manuscript.

Funding: This research was conducted within the projects GRE-16-08 and GRE17-12 coordinated by the University of Alicante. Antonio Jodar-Abellan acknowledges financial support received from the Spanish FPU scholarship for the training of university teachers. In the same way, this work was funded partially by the Cátedra del Agua of the University of Alicante and the Diputación Provincial de Alicante (https://catedradelaguaua.org/).

Conflicts of Interest: The authors declare no conflicts of interest. The funders had no role in the design of the study; in the collection, analyses or interpretation of data; in the writing of the manuscript or in the decision to publish the results.

\section{References}

1. IEA. World Energy Outlook 2019; IEA: Paris, France, 2019; pp. 1-785. Available online: https://www.iea.org/ reports/world-energy-outlook-2019 (accessed on 21 September 2019).

2. Larsen, M.A.D.; Drews, M. Water use in electricity generation for water-energy nexus analyses: The European case. Sci. Total Environ. 2019, 651, 2044-2058. [CrossRef] [PubMed]

3. Bijl, D.L.; Bogaart, P.W.; Kram, T.; de Vries, B.J.M.; van Vuuren, D.P. Long-term water demand for electricity, industry and households. Environ. Sci. Policy 2016, 55, 75-86. [CrossRef] 
4. IEA. Water Energy Nexus. In Excerpt from the World Energy Outlook 2017; IEA: Paris, France, 2017; pp. 1-985. Available online: https://www.iea.org/reports/water-energy-nexus (accessed on 14 May 2018).

5. EC Communication from the commission to the European Parliament; The European council; the European economic and social committee; the committee of the regions and the European investment bank. A Clean Planet for All A European Strategic Long-Term Vision for a Prosperous, Modern, Competitive and Climate Neutral Economy-Transport Aspects; Council of the European Union: Brussels, Belgium, 2018.

6. Llamas, M.R.; Martínez-Santos, P. Intensive groundwater use: Silent revolution and potential source of social conflicts. J. Water Resour. Plan. Manag. 2005, 131, 337-341. [CrossRef]

7. Corominas, J. Agua y energía en el riego, en la época de la sostenibilidad. Ing. del Agua 2010, 17, $219-233$. [CrossRef]

8. Hardy, L.; Garrido, A.; Sirgado, L.J. Análisis y Evaluación de las Relaciones entre el agua y la Energía en España; Fundación Marcelino Botín Santander: Cantabria, Spain, 2010.

9. Scardigno, A. New solutions to reduce water and energy consumption in crop production: A water-energyfood nexus perspective. Curr. Opin. Environ. Sci. Health 2020, 13, 11-15. [CrossRef]

10. Cabrera, E.; Gómez, E.; Soriano, J.; del Teso, R. Eco-layouts in water distribution systems. J. Water Resour. Plan. Manag. 2018, 145, 1-11. [CrossRef]

11. Moreno, M.A.; Córcoles, J.I.; Tarjuelo, J.M.; Ortega, J.F. Energy efficiency of pressurised irrigation networks managed on-demand and under a rotation schedule. Biosyst. Eng. 2010, 107, 349-363. [CrossRef]

12. Jiménez-Bello, M.A.; Alzamora, F.M.; Soler, V.B.; Ayala, H.J.B. Methodology for grouping intakes of pressurised irrigation networks into sectors to minimise energy consumption. Biosyst. Eng. 2010, 105, 429-438. [CrossRef]

13. Fernández García, I.; Moreno, M.A.; Rodríguez Díaz, J.A. Optimum pumping station management for irrigation networks sectoring: Case of Bembezar MI (Spain). Agric. Water Manag. 2014, 144, 150-158. [CrossRef]

14. Moradi-Jalal, M.; Karney, B.W. Optimal design and operation of irrigation pumping stations using mathematical programming and Genetic Algorithm (GA). J. Hydraul. Res. 2008, 46, 237-246. [CrossRef]

15. Price, E.; Ostfeld, A. Discrete pump scheduling and leakage control using linear programming for optimal operation of water distribution systems. J. Hydraul. Eng. 2014, 140, 4014017. [CrossRef]

16. Fereres, E.; Soriano, M.A. Deficit irrigation for reducing agricultural water use. J. Exp. Bot. 2007, 58, 147-159. [CrossRef] [PubMed]

17. Greaves, G.E.; Wang, Y.-M. Identifying irrigation strategies for improved agricultural water productivity in irrigated maize production through crop simulation modelling. Sustainability 2017, 9, 630. [CrossRef]

18. Buono da Silva Baptista, V.B.S.; Córcoles, J.I.; Colombo, A.; Moreno, M.Á. Feasibility of the Use of Variable Speed Drives in Center Pivot Systems Installed in Plots with Variable Topography. Water 2019, 11, 2192. [CrossRef]

19. Khadra, R.; Moreno, M.A.; Awada, H.; Lamaddalena, N. Energy and Hydraulic Performance-Based Management of Large-Scale Pressurized Irrigation Systems. Water Resour. Manag. 2016, 30, 3493-3506. [CrossRef]

20. Lamaddalena, N.; Khila, S. Energy saving with variable speed pumps in on-demand irrigation systems. Irrig. Sci. 2012, 30, 157-166. [CrossRef]

21. García, I.F.; Montesinos, P.; Poyato, E.C.; Díaz, J.A.R. Methodology for Detecting Critical Points in Pressurized Irrigation Networks with Multiple Water Supply Points. Water Resour. Manag. 2014, 28, 1095-1109. [CrossRef]

22. Langarita, R.; Sánchez Chóliz, J.; Sarasa, C.; Duarte, R.; Jiménez, S. Electricity costs in irrigated agriculture: A case study for an irrigation scheme in Spain. Renew. Sustain. Energy Rev. 2017, 68, 1008-1019. [CrossRef]

23. Lecina, S.; Isidoro, D.; Playán, E.; Aragüés, R. Irrigation modernization and water conservation in Spain: The case of Riegos del Alto Aragón. Agric. Water Manag. 2010, 97, 1663-1675. [CrossRef]

24. Zhao, R.-H.; Zhang, Z.-H.; He, W.-Q.; Lou, Z.-K.; Ma, X.-Y. Synthetical Optimization of a Gravity-Driven Irrigation Pipeline Network System with Pressure-Regulating Facilities. Water 2019, 11, 1112. [CrossRef]

25. Carravetta, A.; Del Giudice, G.; Fecarotta, O.; Ramos, H.M. Energy production in water distribution networks: A PAT design strategy. Water Resour. Manag. 2012, 26, 3947-3959. [CrossRef]

26. Pérez-Sánchez, M.; Sánchez-Romero, F.J.; López-Jiménez, P.A.; Ramos, H.M. PATs selection towards sustainability in irrigation networks: Simulated annealing as a water management tool. Renew. Energy 2018, 116, 234-249. [CrossRef]

27. García, I.F.; Novara, D.; Mc Nabola, A. A Model for Selecting the Most Cost-Effective Pressure Control Device for More Sustainable Water Supply Networks. Water 2019, 11, 1297. [CrossRef] 
28. Gorjian, S.; Zadeh, B.N.; Eltrop, L.; Shamshiri, R.R.; Amanlou, Y. Solar photovoltaic power generation in Iran: Development, policies, and barriers. Renew. Sustain. Energy Rev. 2019, 106, 110-123. [CrossRef]

29. Closas, A.; Rap, E. Solar-based groundwater pumping for irrigation: Sustainability, policies, and limitations. Energy Policy 2017, 104, 33-37. [CrossRef]

30. Mincotur. Precio neto de la electricidad para uso doméstico y uso industrial Euros/kWh. Available online: https://www.mincotur.gob.es/es-ES/IndicadoresyEstadisticas/DatosEstadisticos/IV.Energíayemisiones/ IV_12.pdf (accessed on 20 September 2004).

31. Pardo, M.A.; Manzano, J.; Cabrera, E.; García-Serra, J. Energy audit of irrigation networks. Biosyst. Eng. 2013, 115. [CrossRef]

32. Navajas, J.M.N.; Montesinos, P.; Poyato, E.C.; D'iaz, J.A.R. Impacts of irrigation network sectoring as an energy saving measure on olive grove production. J. Environ. Manag. 2012, 111, 1-9. [CrossRef]

33. Replogle, J.A.; Kruse, E.G. Delivery and Distribution Systems. In Design and Operation of Farm Irrigation Systems, 2nd ed.; American Society of Agricultural and Biological Engineers: St. Joseph, MI, USA, 2007; pp. 347-391.

34. Pardo, M.A.; Manzano, J.; Valdés-Abellán, J.; Cobacho, R. Standalone direct pumping photovoltaic system or energy storage in batteries for supplying irrigation networks. Cost analysis. Sci. Total Environ. 2019, 673, 821-830. [CrossRef]

35. Jiménez-Bello, M.A.; Royuela, A.; Manzano, J.; Prats, A.G.; Martínez-Alzamora, F. Methodology to improve water and energy use by proper irrigation scheduling in pressurised networks. Agric. Water Manag. 2015, 149, 91-101. [CrossRef]

36. Goldberg, D.E. Genetic Algorithms in Search, Optimization and Machine Learning, 1st ed.; Addison-Wesley Longman Publishing Co., Inc.: Boston, MA, USA, 1989; ISBN 0201157675.

37. Haq, Z.U.; Anwar, A.A. Irrigation scheduling with genetic algorithms. J. Irrig. Drain. Eng. 2010, 136, 704-714. [CrossRef]

38. Wardlaw, R.; Bhaktikul, K. Application of genetic algorithms for irrigation water scheduling. Irrig. Drain. J. Int. Comm. Irrig. Drain. 2004, 53, 397-414. [CrossRef]

39. Rossman, L.A. EPANET 2: Users Manual; United States Environmental Protection Agency: Washington, DC, USA, 2000.

40. Pardo, M.A.; Riquelme, A.; Melgarejo, J. A tool for calculating energy audits in water pressurized networks. AIMS Environ. Sci. 2019, 6, 94-108.

41. Cabrera, E.; Pardo, M.A.; Cobacho, R.; Arregui, F.J.; Cabrera, E., Jr. Evaluation of carbon credits saved by water losses reduction in water networks. In Proceedings of the IWA International Conference on Water losses, Cape Town, South Africa, 26-30 April 2009.

42. Mirjalili, S.; Dong, J.S.; Sadiq, A.S.; Faris, H. Genetic algorithm: Theory, literature review, and application in image reconstruction. In Nature-Inspired Optimizers; Springer: Berlin/Heidelberg, Germany, 2020; pp. 69-85.

43. Conn, A.R.; Gould, N.I.M.; Toint, P. A globally convergent augmented Lagrangian algorithm for optimization with general constraints and simple bounds. SIAM J. Numer. Anal. 1991, 28, 545-572. [CrossRef]

44. Conn, A.; Gould, N.; Toint, P. A globally convergent Lagrangian barrier algorithm for optimization with general inequality constraints and simple bounds. Math. Comput. 1997, 66, 261-288. [CrossRef]

45. Guo, S.; Zhang, F.; Zhang, C.; An, C.; Wang, S.; Guo, P. A Multi-Objective Hierarchical Model for Irrigation Scheduling in the Complex Canal System. Sustainability 2019, 11, 24. [CrossRef]

46. Mascagni, M.; Srinivasan, A. Parameterizing parallel multiplicative lagged-Fibonacci generators. Parallel Comput. 2004, 30, 899-916. [CrossRef]

47. Ebara Grupos de Presión Automáticos. Available online: http://www.ebara.es (accessed on 15 May 2019).

48. RED Eletcrica de Espana. The Spanish Electricity System 2017; RED Eletcrica de Espana: Madrid, Spain, 2018.

49. Wakeel, M.; Chen, B. Energy consumption in urban water cycle. Energy Procedia 2016, 104, 123-128. [CrossRef]

50. Hoffman, G.J.; Evans, R.G.; Jensen, M.E.; Martin, D.L.; Elliott, R.L. Design and Operation of Farm Irrigation Systems; American Society of Agricultural and Biological Engineers: St. Joseph, MI, USA, 2007.

(C) 2020 by the authors. Licensee MDPI, Basel, Switzerland. This article is an open access article distributed under the terms and conditions of the Creative Commons Attribution (CC BY) license (http://creativecommons.org/licenses/by/4.0/). 